\title{
Relationships between rheumatoid cells in culture
}

\author{
D. G. PALMER \\ From the Rheumatic Diseases Unit, Wellcome Medical Research Institute, Department of Medicine, \\ University of Otago Medical School, Dunedin, New Zealand
}

\begin{abstract}
Palmer D. G. (1975). Annals of the Rheumatic Diseases, 34, 235-238. Relationships between rheumatoid cells in culture. Rheumatoid synovial fluid macrophages are compatible with synovial membrane fibroblasts in mixed cell culture. They do not appear to have had any immunological experience recognized by homologous rheumatoid blood lymphocytes. The fusion between macrophages which often takes place in cultures of rheumatoid synovial fluid cells seems to be the result of a cell membrane change between contiguous cells rather than to the release of a 'fusion factor'. Other combinations and manipulations of the rheumatoid cell population may yet prove fruitful in the search for cell-associated phenomena important in the pathogenesis of rheumatoid disease.
\end{abstract}

The possibility that interactions between the various cell populations present within the inflamed synovial membrane and synovial fluid might be of importance in the pathogenesis of rheumatoid disease has not been widely explored. A possible factor is that a cellassociated antigen of pathogenic importance might be shown.

A recent investigation (Griffiths and Williams, 1974) showed that synovial fluid lymphocytes were stimulated by rheumatoid blood lymphocytes, which might be expected if the former had been sensitized to an antigen associated with the latter. In this report three experimental situations involving mixed populations of rheumatoid cells are presented. The cell populations chosen for co-cultivation reflected earlier observations. (1) It had been previously noted that cultures of macrophages derived from the fluid of osteoarthrotic joints became overgrown by fibroblasts. In contrast, syncytial masses frequently developed from the predominantly macrophage population in cultures of rheumatoid synovial fluid cells, and fibroblastic proliferation was unusual (Palmer, 1971 ; Panayi, Mackay, Neill, McCormick, Marmion, and Duthie, 1974). (2) The macrophage is regarded as an important intermediary in the events leading to the recognition of antigen by T-lymphocytes (Hersh and Harris, 1968; Seeger and Oppenheim, 1970; Waldron, Horn, and Rosenthal, 1973). A rheumatoid macrophage-associated antigen might thus be recognized by a sensitized rheumatoid lymphocyte population. (3) Macrophages cultured in this laboratory from rheumatoid blood have shown little tendency to fuse. Such macrophages have been used to detect the release of a possible fusion factor from synovial fluid macrophage syncytia.

\section{Materials and methods}

CELL CULTURE

Cultures of synovial fluid cells were made from aspirates of knees from patients with rheumatoid arthritis (classical or definite, Ropes, Bennett, Cobb, Jacox, and Jessar, 1959) by a technique involving dilution of the fluid, centrifugation, resuspension in culture medium, and distribution on to Melinex* squares (Palmer, 1971). Synovial membrane fibroblasts were derived from normal (menisectomy) or rheumatoid synovial membrane (synovectomy) by the explant technique. Rheumatoid blood macrophages were obtained from the white cell fraction of heparinized blood samples sedimented with gelatin (Coulson and Chalmers, 1964). Blood lymphocytes were separated from heparinized blood by gradient centrifugation (Perper, Zee, and Mickelson, 1968). Cultures were maintained at $37^{\circ} \mathrm{C}$ in medium 199 supplemented by $20 \%$ serum (heat-inactivated human serum and untreated fetal calf serum 15:5). Blast transformation was sought in smears of lymphocytes stained by the May-Grünwald-Giemsa technique after exposure for 6 days to live rheumatoid synovial macrophage cultures or to suspensions of disrupted macrophages (sonicated or freeze-thawed).

In addition, blood lymphocytes were cultured in the presence of $0.1 \mathrm{ml}$ aliquots of disrupted rheumatoid synovial fluid macrophages (serially diluted $1-1 / 16$ ) released at the 7th day of culture from Carrel flasks by freezing and agitation of the thawing sludge. Incorporation of tritiated thymidine ${ }^{3} \mathrm{HT}$ into these lymphocytes was followed by exposing 6-day triplicate cultures to $0 \cdot 5 \mu \mathrm{Ci}^{3} \mathrm{HT}$ for $24 \mathrm{~h}$. After a further $24 \mathrm{~h}$ the lymphocyte suspension was retrieved on Whatman chromatography glass filter pads,

*Melinex plastic sheet, ICI. 
washed three times with saline followed by $5 \%$ trichloracetic acid and finally with methanol. The residual radioactivity was counted in a Beckman scintillation counter.

\section{Results}

(1) RHEUMATOID SYNOVIAL FLUID

MACROPHAGES AND SYNOVIAL MEMBRANE FIBROBLASTS

Cultures of synovial membrane fibroblasts added to 7-day-old cultures of rheumatoid synovial fluid macrophages grew readily whether or not the former were derived from normal synovial membrane (6 experiments), or from rheumatoid synovial membrane ( 9 experiments) and in the latter case, whether or not the fibroblasts were autologous (1 experiment) or homologous with the macrophages (Fig. 1).

\section{(2) RHEUMATOID SYNOVIAL FLUID}

MACROPHAGES AND BLOOD LYMPHOCYTES

Blood lymphocytes from normal donors and from patients with rheumatoid disease (both autologous and homologous with the test macrophages) cultured in the presence of either rheumatoid synovial fluid macrophage monolayers or macrophages disrupted by sonication showed no morphological evidence of blast transformation (10 experiments). ${ }^{3} \mathrm{HT}$ uptake was not above control levels in two experiments in which rheumatoid lymphocytes were exposed to live homologous rheumatoid macrophages, or in two other experiments in which the macrophages were disrupted by freeze-thawing.

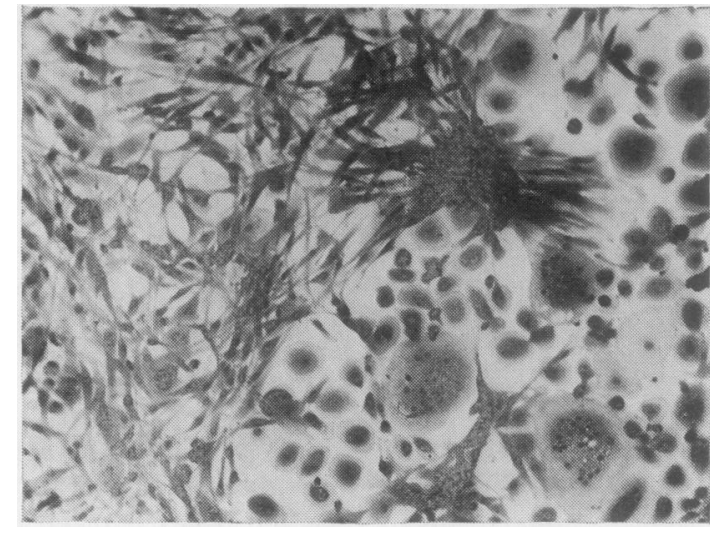

FIG. 1 Normal synovial membrane fibroblasts 7 days after overlay on a culture of rheumatoid synovial fluid macrophages. $\times 174$

(3) BLOOD MACROPHAGES AND RHEUMATOID SYNOVIAL FLUID MACROPHAGES

When 7-day-old cultures of rheumatoid synovial fluid macrophages showing the formation of syncytia were cultured for up to $\mathbf{1 4}$ days in the same vessel as either normal or rheumatoid blood macrophages, n£ fusion between the cells of blood origin above con trol appearances was induced (Fig. 2) (6 experiments)

\section{Discussion}

The series of experiments described in this paper were undertaken to test three situations established in
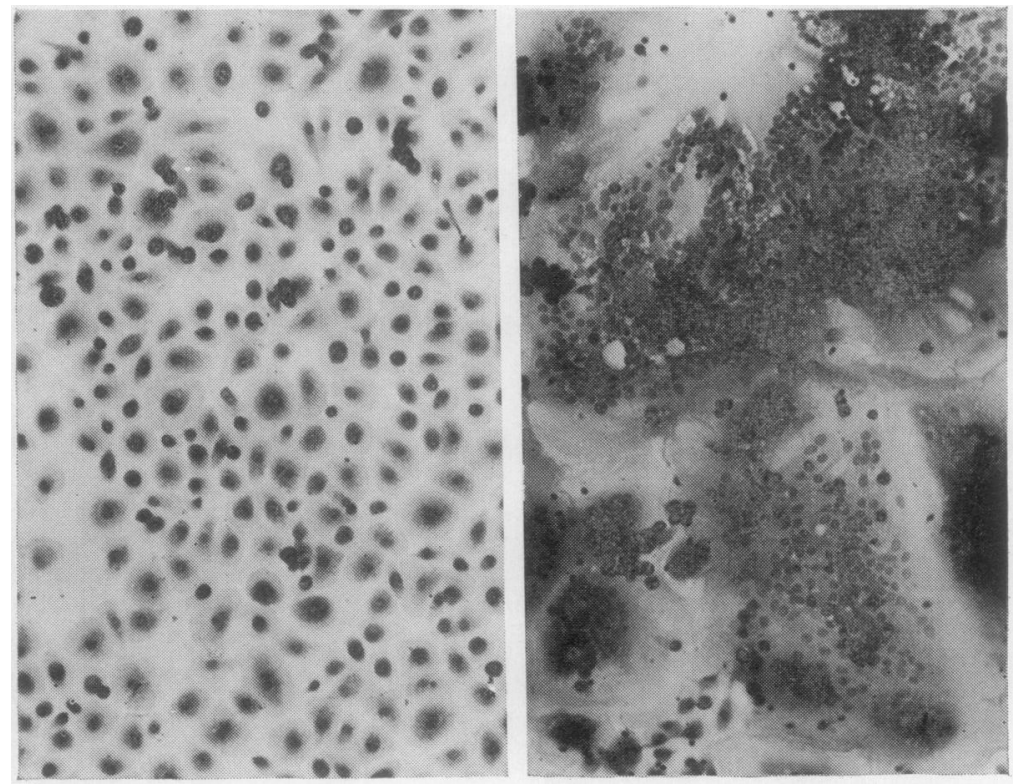

FIG. 2 Co-cultivation of rheumatoid blood macrophages (left) and fused synovial fluid macrophages (right) did not produce significant polykaryocytosis in the cells of blood origin. $\times 174$ 
vitro, under which interaction between particular rheumatoid cell populations might take place.

The absence of fibroblast-type cells from cultures of rheumatoid synovial fluid could conceivably result from a cytotoxic effect by the macrophage population (Zembala, Ptak and Hanczakowska, 1973). In fact, the rheumatoid synovial fluid macrophage and synovial membrane fibroblast appear to be compatible in culture. The implication is either that cells with fibroblastic potential usually form an insignificant percentage of the rheumatoid synovial fluid cell population, or that lymphocyte cytotoxicity (Maclennan and Loewi, 1970) against these cells is expressed before cultures are fully established. Lymphocytes are progressively lost from cultures with changes of media.

No evidence was obtained from the mixed synovial fluid macrophage blood lymphocyte experiments to suggest that the rheumatoid macrophage harboured an antigen recognized by rheumatoid blood lymphocytes. A number of reservations related to this negative result must be expressed. 1 Recent work has suggested that it may be important for the macrophage and lymphocyte populations used in such experiments to be autologous (Rosenthal and Shevach, 1973). 2 Recognition of blast cells in smears which contain detached macrophages can be difficult. 3 It is possible that a population of sensitized lymphocytes in rheumatoid disease should be sought in the synovial fluid itself rather than in the blood (Griffiths and Williams, 1974). 4 The ratio of cell numbers in the two cell populations used in this type of experiment is important (Davie, Rosenthal, and Paul, 1971). The cultured macrophage is difficult to deal with in a quantitative manner due principally to the tenacity with which it adheres to the interior of the culture vessel.

Attention has been drawn previously to the similarity between the syncytial masses formed by the fusion of rheumatoid synovial macrophages and the cytopathic effect of a number of viruses (Palmer, 1970). It seems that this phenomenon is not due to a fusion factor released into the culture medium, but rather is dependent upon a membrane effect between contiguous cells. Mackay, Panayi, Neill, Robinson, Smith, Marmion, and Duthie (1974) have noted the possible immunological implications of polykaryocyte formation from rheumatoid macrophages (Galindo, 1972)-a mechanism which lends itself to investigation. It may be of significance in this context that cell fusion between macrophages in trypsin dispersed cultures of rheumatoid synovial membrane is seen with greater regularity and to a greater extent than is usually seen in rheumatoid synovial fluid cultures (Palmer, 1970).

This work was supported by the Medical Research Council of New Zealand. The capable technical help of Mrs. C. Prendergast is gratefully acknowledged.

\section{References}

Coulson, A. S., AND Chalmers, D. G. (1964) Lancet, 1, 468 (Separation of viable lymphocytes from human blood)

Davie, J. M., Rosenthal, A. S., AND PaUl, W. E. (1971). J. exp. Med., 134, 517 (Receptors on immunocompetent cells; 3 : specificity and nature of receptors on dinitrophenylated guinea pig albumin - ${ }^{125} \mathrm{I}$-binding cells of immunized guinea pigs)

GALINDO, B. (1972) Infect. and Immun., 5, 583 (Antigen-mediated fusion of specifically sensitized rabbit alveolar macrophages)

Griffiths, M. M., AND Williams, R. C. (1974) Arthr. and Rheum., 17, 111 (In vitro peripheral blood and synovial fluid lymphocyte interactions)

Hersh, E. M., AND HARRIS, J. E. (1968) J. Immunol., 100, 1184 (Macrophage-lymphocyte interaction in the antigeninduced blastogenic response of human peripheral blood leukocytes)

Mackay, J. M. K., Panayi, G., Neill, W. A., Robinson, A., Smith, W., Marmion, B. P., and Duthie, J. J. R. (1974) Ann. rheum. Dis., 33, 225 (Cytology of rheumatoid synovial cells in culture. I. Composition and sequence of cell populations in cultures of rheumatoid synovial fluid)

MACLENNAN, I. C. M., AND LOEWI, G. (1970) Clin. exp. Immunol., 6, 713 (The cytotoxic activity of mononuclear cells from joint fluid)

PaLmer, D. G. (1970) Acta rheum. scand., 16, 261 (Dispersed cell cultures of rheumatoid synovial membrane)

- (1971) Proc. Univ. Otago med. Sch., 49, 18 (The differentiation of cells cultured from synovial effusions)

Panayi, G. S., Mackay, J. M. K., Neill, W. A., McCormick, J. N., Marmion, B. P., and Duthie, J. J. R. (1974) Ann. rheum. Dis., 33, 234 (Cytology of rheumatoid synovial cells in culture. II. Association of polykaryocytes with rheumatoid and other forms of arthritis)

PerPer, R. J., Zee, T. W., AND Mickelson, M. M. (1968) J. Lab. clin. Med., 72, 842 (Purification of lymphocytes and platelets by gradient centrifugation)

Ropes, M. W., Bennett, G. A., CobB, S., JAcox, R., AND Jessar, R. A. (1959) Arthr. and Rheum., 2, 16 (1958 revision of diagnostic criteria for rheumatoid arthritis)

Rosenthal, A. S. AND SheVACH, E. M. (1973) J. exp. Med., 138, 1194 (Function of macrophages in antigen recognition by guinea pig $\mathrm{T}$ cells. 1. Requirement for histccompatible macrophages and lymphocytes) 
SEEGER, R. C., AND OPPENHEIM, J. J. (1970) Ibid., 132, 44 (Synergistic interaction of macrophages and lymphocytes in antigen-induced transformation of lymphocytes)

Waldron, J. A., Horn, R. G., AND Rosenthal, A. S. (1973) J. Immunol., 111, 58 (Antigen-induced proliferation of guinea pig lymphocytes in vitro: obligatory role of macrophages in the recognition of antigen by immune T-lymphocytes)

Zzmbala, M., Ptak, W., and HanczakowsKa, M. (1973) Clin. exp. Immunol., 15, 461 (Macrophage and lymphocyte co-operation in target cell destruction in vitro) 